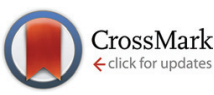

Cite this: Org. Chem. Front., 2016, 3, 625

Received 4th February 2016,

Accepted 11th March 2016

DOI: $10.1039 / c 6 q 000057 f$

rsc.li/frontiers-organic

\title{
Heterocycle-derived $\beta$-S-enals as bifunctional linchpins for the catalytic synthesis of saturated heterocycles $\uparrow$
}

\author{
Jingze Niu and Michael C. Willis*
}

We demonstrate how heterocycle-derived $\beta$-S-enals can be employed as bifunctional substrates in a cascade of two rhodium-catalysed $\mathrm{C}-\mathrm{C}$ bond forming reactions to deliver substituted heterocyclic products. A single rhodium-catalyst, generated in situ from a commercial salt and ligand combination, is used to promote both an initial alkene or alkyne hydroacylation reaction, and then a Suzuki-type cross-coupling, resulting in a three-component assembly of the targeted heterocycles. Substrates based on $\mathrm{N}$-, Oand S-heterocycles are included, as are a range of alkenes, alkynes and boronic acid derivatives.

Due to the favourable physiochemical properties often associated with their incorporation into candidate structures, saturated, or partially saturated, heterocycles are becoming increasingly targeted in drug discovery programs. ${ }^{1}$ Their presence in biologically active molecules has significant precedent, and Scheme 1 shows several examples of $\mathrm{N}$-, $\mathrm{O}$ - and S-heterocycles embedded in pharmaceuticals and natural products used in a variety of applications. ${ }^{2}$ The N-based congeners such as pyrrolidines, piperidines, and tropanes are the most commonly encountered structures. ${ }^{3}$

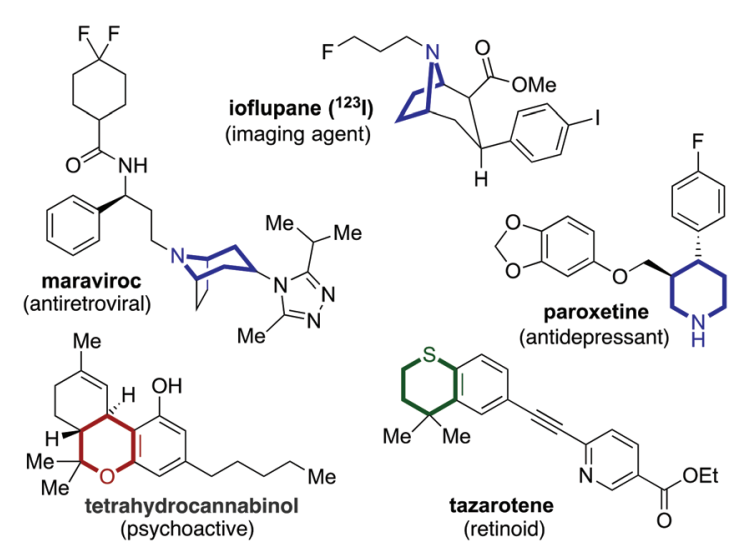

Scheme 1 Saturated and partially saturated heterocycles in pharmaceuticals and natural products.

Department of Chemistry, University of Oxford, Chemical Research Laboratory, Mansfield Road, Oxford, OX1 3TA, UK. E-mail: michael.willis@chem.ox.ac.uk $\dagger$ Electronic supplementary information (ESI) available: Experimental details and supporting characterisation data. See DOI: 10.1039/c6qo00057f
In order to access saturated and partially saturated heterocycles decorated with a variety of substituents, we conceived an approach based on a common class of bifunctional building blocks that could be elaborated using cascade catalytic reactions. The key building blocks that we settled on were heterocycle-derived $\beta$-S-enals (1, Scheme 2). Variants of $\mathbf{1}$ featuring $\mathrm{N}, \mathrm{O}$, and S-atoms are all accessible from the parent ketones using established methods. ${ }^{4}$ With the key building blocks available we speculated that a single rhodium-catalyst could mediate an initial alkene or alkyne hydroacylation reaction, ${ }^{5}$ and then a Suzuki-type cross-coupling, to convert enals 1 into difunctionalised products 2 in a single step, joining together three separate components. A variety of methods could then be used to convert enones 2 into the fully saturated heterocycles. The design of the $\beta$-S-enals allows the S-atom to function as the directing atom for the initial chelation-controlled hydroacylation reaction, and then for the O-atom of the resul-

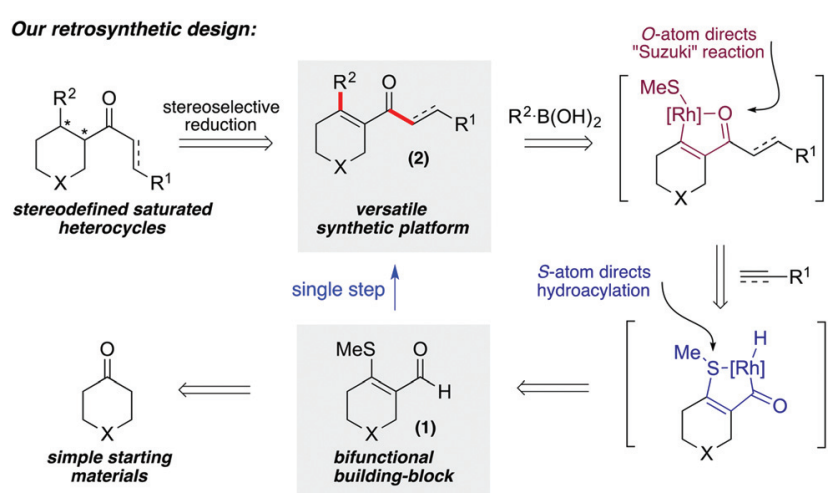

Scheme 2 Heterocycle-derived $\beta$-S-enals as building blocks towards saturated heterocycles. 


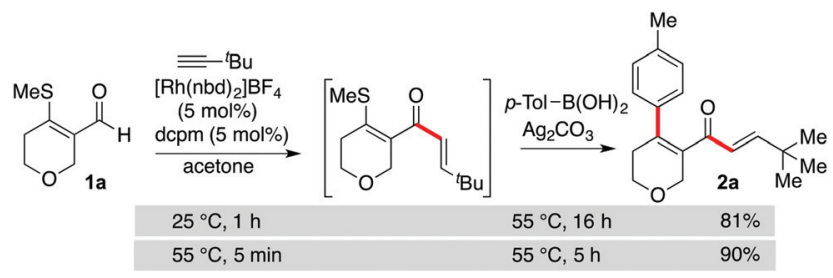

Scheme 3 Establishing reaction conditions for the hydroacylationSuzuki cascade sequence to prepare dihydropyran $2 a$.

tant enone to direct the Suzuki-type coupling. The use of aldehydes with $\beta$-S-directing groups in hydroacylation reactions is well established. ${ }^{6-9}$ In addition, our laboratory, ${ }^{10}$ and others, ${ }^{11}$ has recently reported on the required aryl methyl sulfide Suzuki chemistry, including a cascade reaction on a benzenederived substrate.

We began by evaluating the basic reaction sequence using pyran-derived enal 1a, tert-butyl acetylene and $p$-tolyl boronic acid as the reaction partners (Scheme 3). Earlier precedent, ${ }^{10,12}$ and initial investigations, ${ }^{13}$ suggested that a $\mathrm{Rh}(\mathrm{I})$ catalyst incorporating the small-bite-angle bis-phosphine ligand dcpm should be able to mediate both of the key $\mathrm{C}-\mathrm{C}$ bond forming reactions. When a catalyst of this type was generated in situ and applied to the targeted transformation, good yields of enone 2a were obtained. Achieving a short reaction time for the initial hydroacylation reaction was key to obtaining a high yield for the final product. Accordingly, warming to $55{ }^{\circ} \mathrm{C}$ resulted in the hydroacylation reaction being complete in only 5 minutes, with the following Suzuki-type coupling then requiring 5 hours. It was pleasing to note that the $\beta$-S-enal substrate appeared to allow significantly faster reactions than the previously explored fully aromatic system.

With a catalyst and appropriate reaction conditions for the cascade process in hand, we next explored the scope of the alkynes and alkenes that could be employed in the hydroacylation step. Given the importance of N-heterocycles in medicinal chemistry, we chose the tetrahydropyridine substrate, $\mathbf{1 b}$, in combination with tolyl boronic acid, as a suitable platform to evaluate the chemistry (Scheme 4). As can be seen the use of tert-butyl acetylene was successful, delivering the three-component product, enone $\mathbf{2 b}$, in high yield. A terminal alkyne substituted with a benzyl ether (2c), and an internal alkyne (2d) were both successful substrates. Less sterically demanding alkyne substrates resulted in mixtures of linear and branched regioisomers in the hydroacylation step, resulting in lower overall yields. For example, phenyl acetylene (2e) and hex-5ynenitrile (2f) delivered $4: 1$ and 5:1 mixtures of linear: branched isomers, respectively. Terminal alkenes could be employed in the desired cascade process, however, their lower reactivity in the hydroacylation step, relative to alkynes, necessitated the use of five equivalents to achieve suitably fast reactions. Using these conditions with octene delivered the desired three-component coupled product $(\mathbf{2 g})$ in $84 \%$ yield. Terminal alkenes substituted with bromo (2h), phenyl (2i) and

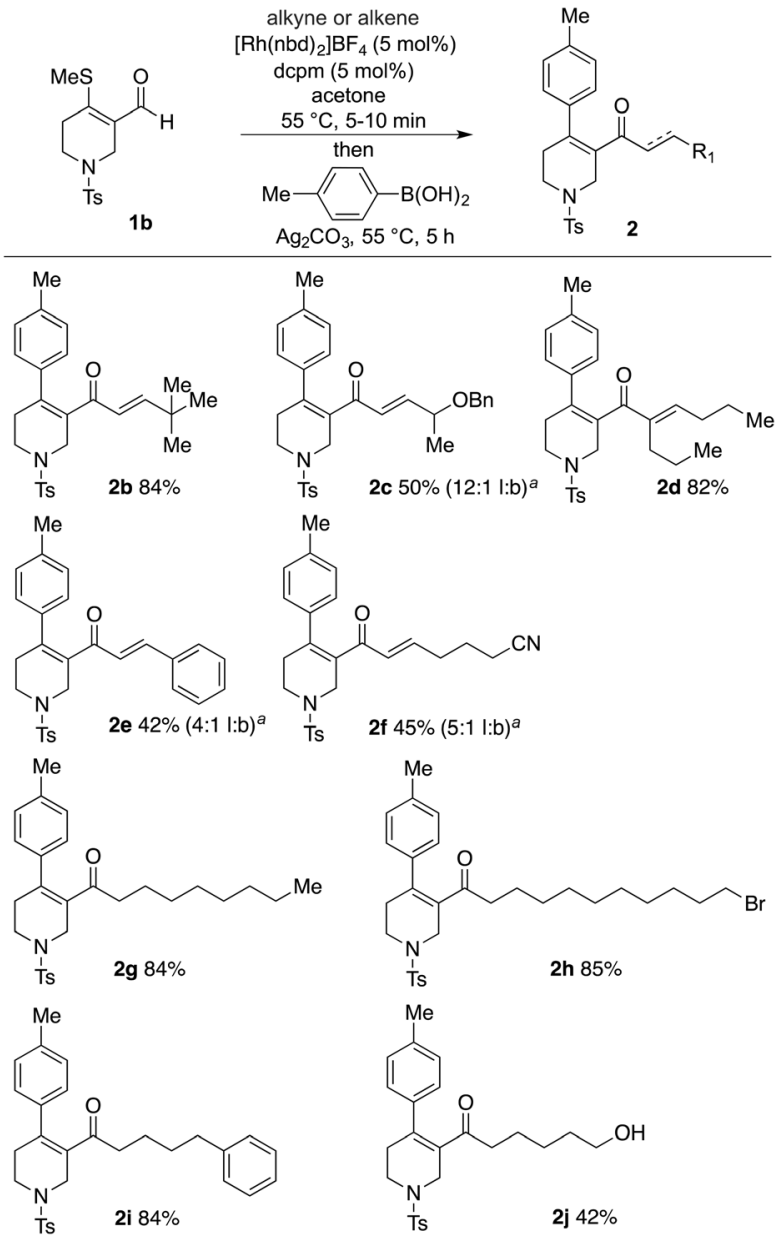

Scheme 4 Substrate scope of the alkyne and alkene component in the cascade synthesis of tetrahydropyridines 2 . Reaction conditions: 1 b $(1.0$ equiv.), alkyne (1.5 equiv.) or alkene (5.0 equiv.), $\left[\mathrm{Rh}(\mathrm{nbd})_{2}\right] \mathrm{BF}_{4}(5 \mathrm{~mol} \%)$, dcpm (5 mol\%), acetone, $55^{\circ} \mathrm{C}, 5-10 \mathrm{~min}$; then $p$-tolyl boronic acid (1.5 equiv.), $\mathrm{Ag}_{2} \mathrm{CO}_{3}$ (1.0 equiv.), $55^{\circ} \mathrm{C}, 5 \mathrm{~h}$. Isolated yields of the major isomer. ${ }^{a}$ Measured by ${ }^{1} \mathrm{H}$ NMR spectrometry on the crude reaction mixture.

free hydroxyl groups (2j) were also successfully employed. Disubstituted alkenes were unreactive in the described system. ${ }^{14}$

Tetrahydropyridine enal $\mathbf{1 b}$ was then used to evaluate the scope of the boronic acid coupling partner (Scheme 5). Initially employing tert-butyl acetylene as the hydroacylation coupling partner, a range of electronically varied aryl boronic acids could be readily employed (2k-2p), including halogen substituents. Although substitution at the meta-position was possible (2n), attempts to employ ortho-substituted boronic acids were unsuccessful. A heterocyclic boronic acid, in the form of 3-thienyl, and also an alkenyl boronic acid performed well (2q and 2r). Using octene as the hydroacylation coupling partner allowed a similar range of boronic acids to be successfully incorporated into the cascade process $(2 \mathbf{s}-2 \mathbf{x})$.

One of the goals of the present chemistry was to show that a variety of different heterocycles could be accessed using a single strategy. Accordingly, in Scheme 6 we demonstrate the successful use of $\mathrm{N}-$, O-, and S-based heterocyclic building 


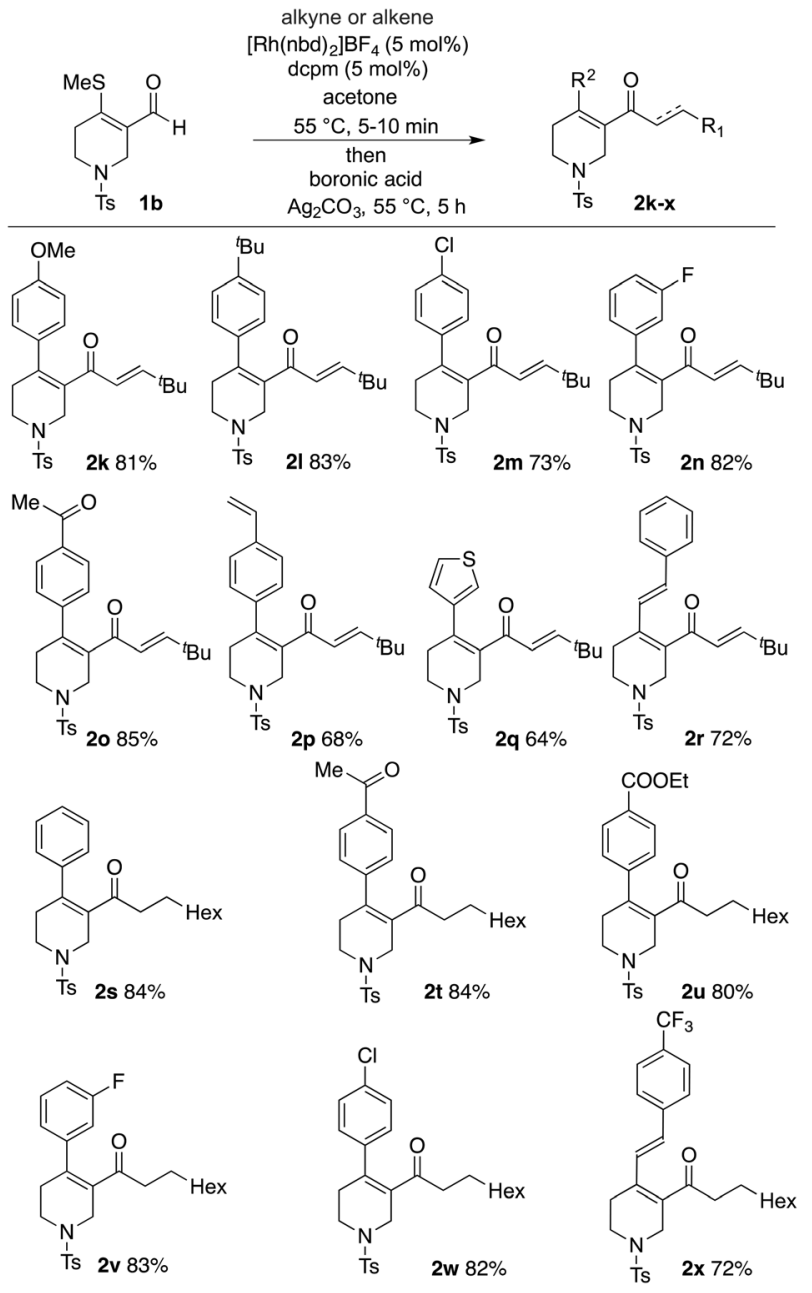

Scheme 5 Substrate scope of the boronic acid component in the cascade synthesis of tetrahydropyridines 2 . Reaction conditions: 1 b (1.0 equiv.), alkyne (1.5 equiv.) or alkene (5.0 equiv.), $\left[\mathrm{Rh}(\mathrm{nbd})_{2}\right] \mathrm{BF}_{4}(5 \mathrm{~mol} \%)$, dcpm (5 mol\%), acetone, $55^{\circ} \mathrm{C}, 5-10 \mathrm{~min}$; then boronic acid (1.5 equiv.), $\mathrm{Ag}_{2} \mathrm{CO}_{3}$ (1.0 equiv.), $55^{\circ} \mathrm{C}, 5 \mathrm{~h}$. Isolated yields.

blocks. For O-based heterocycles, a dihydropyran and a $2 \mathrm{H}^{-}$ chromene-based substrate were both combined successfully with alkene and alkyne coupling partners and aryl boronic acids (2a, 3a-3d). S-heteocycles were represented by a $2 \mathrm{H}$-thiochromene-based substrate, which was employed without incident (3e, 3f). Unfortunately, it was not possible to prepare the dihydrothiopyran substrate due to stability issues. Finally, in addition to tetrahydropyridine substrate $\mathbf{1 b}$ already described, we were able to prepare and exploit a tropane-based substrate (1e), allowing access to alkyne and alkene coupled products in good yields ( $3 \mathbf{g}$ and $\mathbf{3 h}$ ).

All of the scoping experiments described in Schemes 4-6, were performed on a relatively small scale $(0.2 \mathrm{mmol}$ of enal), and as such $5 \mathrm{~mol} \%$ of catalyst was employed due to ease of use. However, for larger preparative scale reactions, it was possible to lower the catalyst loading. Scheme 7 shows the use of tetrahydropyridine substrate $\mathbf{1 b}$, and tropane-derived sub-

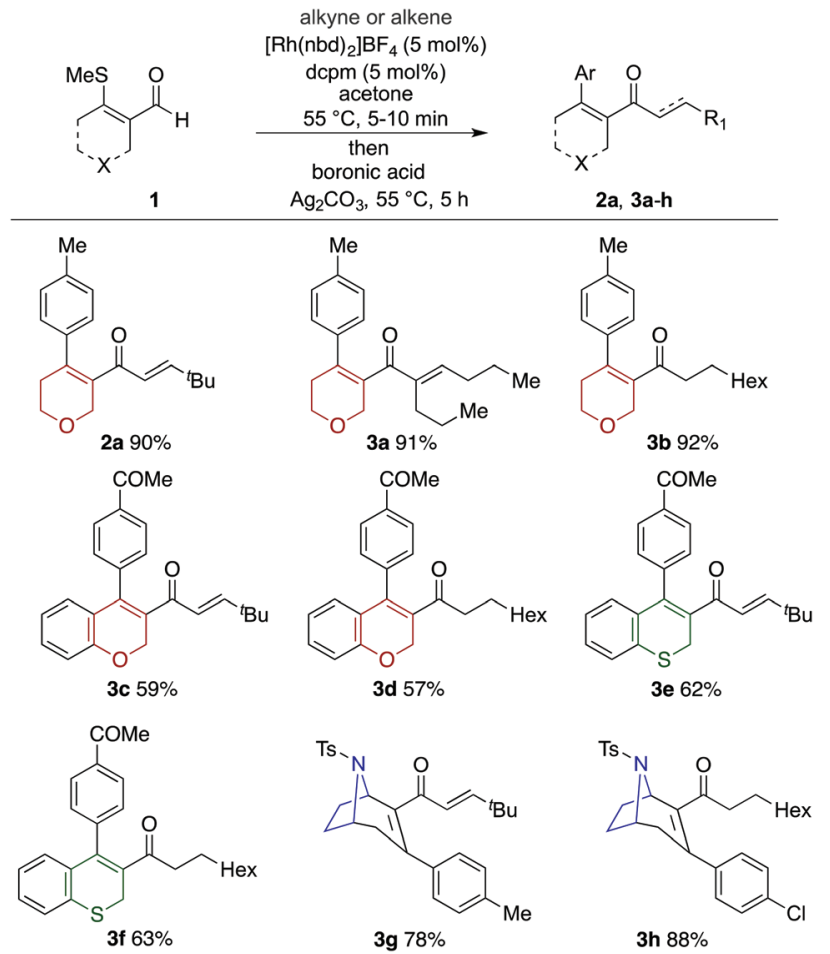

Scheme 6 Variation of the heterocyclic enal component in the preparation of di-coupled products 3 . Reaction conditions: 1 (1.0 equiv.), alkyne (1.5 equiv.) or alkene (5.0 equiv.), $\left[\mathrm{Rh}(\mathrm{nbd})_{2}\right] \mathrm{BF}_{4}(5 \mathrm{~mol} \%)$, dcpm (5 mol\%), acetone, $55^{\circ} \mathrm{C}, 5-10 \mathrm{~min}$; then boronic acid (1.5 equiv.), $\mathrm{Ag}_{2} \mathrm{CO}_{3}$ (1.0 equiv.), $55^{\circ} \mathrm{C}, 5 \mathrm{~h}$. Isolated yields.

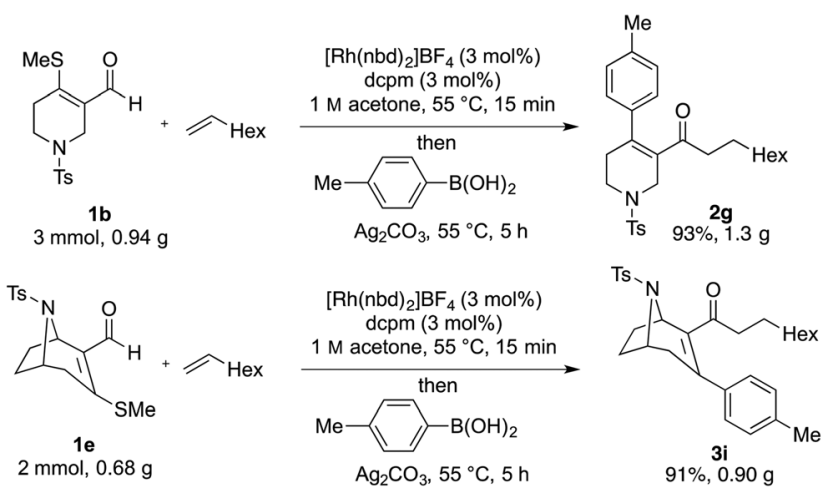

Scheme 7 Preparative scale synthesis of products $2 \mathrm{~g}$ and $3 \mathrm{i}$.

strate 1e, used in alkene hydroacylation initiated cascades, employing just $3 \mathrm{~mol} \%$ of catalyst, to deliver gram scale quantities of coupled products ( $2 \mathbf{g}$ and $\mathbf{3 i}$ ) in excellent yields.

Finally, as an illustration of synthetic potential of the enone products obtained from the developed cascade processes, we have shown that tetrahydropyridine-derived product $2 \mathrm{~g}$ undergoes high-yielding detosylation and alkene reduction in a single-step, providing piperidine 4 (Scheme 8). This one-step 

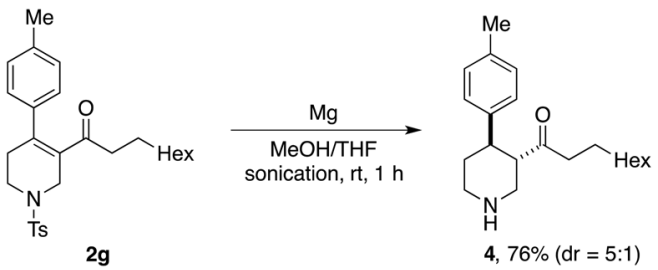

Scheme 8 One-step deprotection and reduction of enone $\mathbf{2 g}$.

transformation was achieved using magnesium metal in methanol under sonication conditons. ${ }^{15}$

In conclusion, we have shown that heterocycle-derived $\beta$-Senals are efficient substrates for rhodium-catalysed hydroacylation-Suzuki type coupling cascade processes. Both alkyne and alkene hydroacylation reactions can be used as the initial $\mathrm{C}-\mathrm{C}$ bond-forming event, and a variety of boronic acids can be employed as substrates in the Suzuki-type coupling. The products are obtained in good to excellent yields, and show potential as precursors to access biologically relevant compounds.

\section{Acknowledgements}

We thank the EPSRC for the award of an Established Career Fellowship (MCW).

\section{Notes and references}

1 (a) T. J. Ritchie, S. J. F. Macdonald, R. J. Young and S. D. Pickett, Drug Discovery Today, 2011, 16, 164; (b) F. Lovering, J. Bikker and C. Humblet, J. Med. Chem., 2009, 52, 6752.

2 (a) Y. Yuan, C. K. Arnatt, N. El-Hage, S. M. Dever, J. C. Jacob, D. E. Selley, K. F. Hauser and Y. Zhang, Med. Chem. Commun., 2013, 4, 847; (b) D. Šakić, F. Achrainer, V. Vrček and H. Zipse, Org. Biomol. Chem., 2013, 11, 4232; (c) Y. Yuan, C. K. Arnatt, G. Li, K. M. Haney, D. Ding, J. C. Jacob, D. E. Selley and Y. Zhang, Org. Biomol. Chem., 2012, 10, 2633; (d) P. C. Meltzer, P. Blundell, T. Zona, L. Yang, H. Huang, A. A. Bonab, E. Livni, A. Fischman and B. K. Madras, J. Med. Chem., 2003, 46, 3483; (e) S. D. Banister, I. A. Moussa, C. Beinat, A. J. Reynolds, P. Schiavini, W. T. Jorgensen and M. Kassiou, Bioorg. Med. Chem. Lett., 2011, 21, 38; (f) R. K. Razdan, Pharmacol. Rev., 1986, 38, 75.

3 (a) E. Vitaku, D. T. Smith and J. T. Njardarson, J. Med. Chem., 2014, 57, 10257; (b) C.-V. T. Vo and J. W. Bode, J. Org. Chem., 2014, 79, 2809.

4 A two-step process is employed, involving initial conversion of the parent ketone into the corresponding $\beta$-halo-enal, followed by substitution of the halogen substituent with a methyl sulfide: D. R. Williams, L. A. Robinson, C. R. Nevill and J. P. Reddy, Angew. Chem., Int. Ed., 2007, 46, 915.
5 (a) M. C. Willis, Chem. Rev., 2010, 110, 725; (b) C.-H. Jun, E.-A. Jo and J.-W. Park, Eur. J. Org. Chem., 2007, 1869.

6 Selected examples: (a) M. C. Willis, S. J. McNally and P. J. Beswick, Angew. Chem., Int. Ed., 2004, 42, 340; (b) M. C. Willis and R. L. Woodward, J. Am. Chem. Soc., 2005, 127, 18012; (c) G. L. Moxham, H. E. Randell-Sly, S. K. Brayshaw, R. L. Woodward, A. S. Weller and M. C. Willis, Angew. Chem., Int. Ed., 2006, 45, 7618; (d) J. D. Osborne and M. C. Willis, Chem. Commun., 2008, 5025; (e) G. L. Moxham, H. Randell-Sly, S. K. Brayshaw, A. S. Weller and M. C. Willis, Chem. - Eur. J., 2008, 14, 8383; $(f)$ S. R. Parsons, J. F. Hooper and M. C. Willis, Org. Lett., 2011, 13, 998; (g) R. Pawley, M. Huertos, G. LloydJones, A. S. Weller and M. C. Willis, Organometallics, 2012, 31, 5650; (h) S.-J. Poingdestre, J. D. Goodacre, A. S. Weller and M. C. Willis, Chem. Commun., 2012, 48, 6354.

7 Examples of alternative chelating groups in intermolecular hydroacylation reactions: O-chelation; (a) K. Kokubo, K. Matsumasa, M. Miura and M. Nomura, J. Org. Chem., 1997, 62, 4564; (b) M. Imai, M. Tanaka, K. Tanaka, Y. Yamamoto, N. Imai-Ogata, M. Shimowatari, S. Nagumo, N. Kawahara and H. Suemune, J. Org. Chem., 2004, 69, 1144; (c) J.-H. Zhang and C. Bolm, Org. Lett., 2011, 13, 3900; (d) M. von Delius, C. M. Le and V. M. Dong, J. Am. Chem. Soc., 2012, 134, 15022; (e) X.-W. Du and L. M. Stanley, Org. Lett., 2015, 17, 3276, N-Chelation; (f) J. W. Suggs, J. Am. Chem. Soc., 1979, 101, 489; (g) C.-H. Jun, H. Lee and J.-B. Hong, J. Org. Chem., 1997, 62, 1200; (h) N. R. Vautravers, D. D. Regent and B. Breit, Chem. Commun., 2011, 47, 6635; (i) T. Zhang, Z. Qi, X. Zhang, L. Wu and X. Li, Chem. - Eur. J., 2014, 20, 3283; (j) M. Castaing, S. L. Wason, B. Estepa, J. F. Hooper and M. C. Willis, Angew. Chem., Int. Ed., 2013, 52, 13280.

8 For a review of non-chelation-controlled hydroacylation reactions: J. C. Leung and M. J. Krische, Chem. Sci., 2012, 3, 2202.

9 Examples of non-chelation-controlled hydroacylation reactions: (a) T. B. Marder, D. C. Roe and D. Milstein, Organometallics, 1988, 7, 1451; (b) T. Kondo, M. Akazome, Y. Tsuji and Y. Watanabe, J. Org. Chem., 1990, 55, 1286; (c) T. Tsuda, T. Kiyoi and T. Saegusa, J. Org. Chem., 1990, 55, 2554; (d) C. P. Lenges, P. S. White and M. Brookhart, J. Am. Chem. Soc., 1998, 120, 6965; (e) A. H. Roy, C. P. Lenges and M. Brookhart, J. Am. Chem. Soc., 2007, 129, 2082; $(f)$ S. Omura, T. Fukuyama, J. Horiguchi, Y. Murakami and I. Ryu, J. Am. Chem. Soc., 2008, 130, 14094; $(g)$ F. Shibahara, J. F. Bower and M. J. Krische, J. Am. Chem. Soc., 2008, 130, 14120; (h) V. M. Williams, J. C. Leung, R. L. Patman and M. J. Krische, Tetrahedron, 2009, 65, 5024; (i) Q.-A. Chen, D. K. Kim and V. M. Dong, J. Am. Chem. Soc., 2014, 136, 3772.

10 J. F. Hooper, R. D. Young, I. Pernik, A. S. Weller and M. C. Willis, Chem. Sci., 2013, 4, 1568.

11 F. Pan, H. Wang, P.-X. Shen, J. Zhao and Z.-J. Shi, Chem. Sci., 2013, 4, 1573. 
12 (a) A. B. Chaplin, J. F. Hooper, A. S. Weller and M. C. Willis, J. Am. Chem. Soc., 2012, 134, 4885; (b) I. Pernik, J. F. Hooper, A. B. Chaplin, A. S. Weller and M. C. Willis, ACS Catal., 2012, 2, 2779.

13 See ESI† for details.
14 A. Prades, M. Fernández, S. D. Pike, M. C. Willis and A. S. Weller, Angew. Chem., Int. Ed., 2015, 54, 8520.

15 B. Nyasse, L. Grehn and U. Ragnarsson, Chem. Commun., 1997, 1017. 